\section{Fight against Ebola disease: strengthening laboratory framework in low resource settings}

\section{Saurabh R. Shrivastava, \\ Prateek S. Shrivastava, Jegadeesh \\ Ramasamy}

Department of Community Medicine, Shri Sathya Sai Medical College and Research Institute, Kancheepuram, India

The 2014 outbreak of Ebola disease has uncovered bitter facts about the prevalent health indicators pertaining to people living in low resource settings. ${ }^{1}$ Although, the enemy Ebola virus - was not new, public health authorities have failed miserably in all the affected regions (Guinea, Sierra Leone, Liberia, Nigeria, and Senegal). ${ }^{1,2}$ Despite the fact that health professionals were able to successfully contain the disease in the last twenty of its emergences in different settings, the current outbreak has proved to be way beyond the coping abilities of the public health care delivery systems. ${ }^{2,3}$ Furthermore, the caseload continued to increase at an exponential rate, with a fatality rate of almost $90 \%$, and the virus did not spare health professionals like doctors and paramedical personnel (who are supposed to be well-equipped in comparison with the common men), and all this happened despite the extension of support from international welfare agencies. ${ }^{4,5}$ Although multiple determinants (poverty, weak public health care delivery system, lack of preparedness, failure to involve the community, no isolation wards/dedicated treatment centers/ vaccine, logistics constraints, etc.) played their part, the inability of the stakeholders to ensure prompt detection of confirmed cases (no designated laboratory), remained the crucial element in allowing the disease to progress to epidemic proportions. . $^{1,6,7}$

The current outbreak is caused by the Zaire species of the genus Ebola virus, ${ }^{8}$ and its existence in humans is essentially confirmed by laboratory investigations [viz. detection of viral RNA by reverse transcriptase polymerase chain reaction (RT-PCR), and/or by detection of Ebola antigen by a specific antigen detection test, and/or by detection of immunoglobulin $\mathrm{M}(\operatorname{Ig} \mathrm{M})$ antibodies directed against Ebola] ${ }^{8,9}$ Establishment of diagnosis carries a lot of importance, as failure to detect even a single case can start a new chain of transmission anywhere around the world, and at the same time can produce an extremely high case fatality rate associated with the disease. ${ }^{3,4}$ By acknowledging the threat associated with the disease, multiple interventions such as exhaustive case and contact finding (viz. establishing the diagnosis in all suspect/prob- able cases), effective response to patients and the community (viz. isolation of patients and symptomatic contacts, appropriate and adequate treatment, contact tracing and monitoring each contact for 21 days after exposure, use of personal protective equipments, and maintenance of hand hygiene), and preventive interventions (viz. infection control in health care settings, community education, and avoiding contact with reservoir species), have been proposed to interrupt the chain of transmission and thus the progression of the disease. . $^{3,4,6,7,10}$

Exhaustive case and contact finding remains the most crucial step in reducing the incidence of Ebola virus disease (EVD) cases, and thus ensuring availability of easily accessible diagnostic services in low-resource setting remains the major cause of public health concern. ${ }^{11}$ In fact, the World Health Organization has strictly advocated for all the unaffected nations to designate laboratories and build a team of trained personnel to perform laboratory activities efficiently. ${ }^{12}$ These designated laboratories are bio-safety level (BSL)4/BSL3 facilities, in which competent medical staff are employed to safely collect the appropriate specimens from the patients or ensure safe handling of dead bodies or human remains for post-mortem examination. ${ }^{9,13}$ However, the success of case finding indirectly depends on the strategy of contact tracing (which assist in prompt identification of symptomatic contacts) in the community, during which if any contact develops symptoms, is immediately referred to the diagnostic laboratories for confirmation of diagnosis of EVD, so that subsequent measures can be initiated. ${ }^{13,14}$ The role of laboratories is not only limited to diagnostic purposes, but it also assists in estimation of the caseload in the catchment area and helps in notification of cases to higher authorities to ensure rational allocation of scarce resources depending on caseload. Moreover, it enables clinicians to discharge patients (on obtaining two negative RT-PCR results done at least 48 hours apart) from hospital (shortage of bed in low resource settings). ${ }^{3,9,10}$ However, amidst all the above mentioned responsibilities, the laboratory personnel should take appropriate preventive measures (e.g. use of personal protective equipments and personal hygiene, etc.) to avoid contracting the illness themselves. ${ }^{9}$

In conclusion, designating laboratories for Ebola virus related work and supporting the same through a team of trained personnel can play an indispensable role in reducing the magnitude of the EVD in low resource settings as well as across the globe.
Correspondence: Saurabh RamBihariLal Shrivastava, Department of Community Medicine, Shri Sathya Sai Medical College and Research Institute, Thiruporur-Guduvancherry main road, 603108 Kancheepuram, India. Tel./Fax: +91.988.422.7224.

E-mail: drshrishri2008@gmail.com

Key words: Ebola virus, laboratories, low-resource settings, public health.

Contributions: SS, conception and design, drafting of the article, review of literature, guarantor PS, drafting of the article, review of literature, critical revision for important intellectual content; JR, general supervision of the research, overall guidance in writing the manuscript.

Conflict of interests: the authors declare no potential conflict of interests.

Received for publication: 28 October 2014. Accepted for publication: 3 November 2014.

This work is licensed under a Creative Commons Attribution 3.0 License (by-nc 3.0).

(C) Copyright S.R. Shrivastava et al., 2014

Licensee PAGEPress, Italy

Healthcare in Low-resource Settings 2014; 2:4800 doi:10.4081/hls.2014.4800

\section{References}

1. Chan M. Ebola virus disease in West Africa - no early end to the outbreak. New Engl J Med 2014;371:1183-5.

2. CDC. Outbreaks chronology: Ebola virus disease. Atlanta, GA, USA: Centers for Disease Control and Prevention; 2014. Available from: http://www.cdc.gov /vhf/Ebola/outbreaks/history/chronology.ht $\mathrm{ml}$

3. Frieden TR, Damon I, Bell BP, et al. Ebola 2014: new challenges, new global response and responsibility. New Engl J Med 2014; 371:1177-80.

4. WHO. Ebola in West Africa: heading for catastrophe? Geneva, Switzerland: World Health Organization; 2014. Available from: http://www.who.int/csr/disease/ebola/ebola -6-months/west-africa/en/

5. Lefebvre A, Fiet C, Belpois-Duchamp C, et al. Case fatality rates of Ebola virus diseases: a meta-analysis of World Health Organization data. Med Maladies Infect 2014;44:412-6.

6. WHO. Ebola virus disease. Fact sheet $\mathrm{N}^{\circ}$ 103. Geneva, Switzerland: World Health Organization; 2014. Available from: http://www.who.int/mediacentre/factsheets/fs103/en/

7. Cheng Y, Li Y, Yu HJ. Ebola virus disease: general characteristics, thoughts, and per- 
spectives. Biomed Environ Sci 10. WHO. WHO response to the Ebola virus 2014;27:651-3.

8. Baize S, Pannetier D, Oestereich L, et al. Emergence of Zaire Ebola virus disease in Guinea. New Engl J Med 2014;371:1418-25.

9. WHO. Laboratory guidance for the diagnosis of Ebola virus disease. Interim recommendations. Geneva, Switzerland: World Health Organization; 2014. disease outbreak: update by the WHO regional director for Africa. Geneva, Switzerland: World Health Organization; 2014.

11. Briand S, Bertherat E, Cox P, et al. The international Ebola emergency. New Engl J Med 2014;371:1180-3.

12. Hwang ES. Preparedness for prevention of
Ebola virus disease. J Korean Med Sci 2014;29:1185.

13. Okeke IN, Manning RS, Pfeiffer T. Diagnostic schemes for reducing epidemic size of African viral hemorrhagic fever outbreaks. J Infect Dev Ctries 2014;8:114859 .

14. Kelly JD. Make diagnostic centres a priority for Ebola crisis. Nature 2014;513:145. 